\title{
Super-dominant right coronary artery, absent left circumflex artery and left anterior descending artery arising from right coronary sinus
}

\author{
Tariq Enezate, Jad Omran, Kul Aggarwal \\ Division of Cardiology, School of Medicine, University of Missouri-Columbia, Columbia, USA
}

Adv Interv Cardiol 2017; 13, 1 (47): 86-87 DOI: https://doi.org/10.5114/aic.2017.66195

\section{Introduction}

Coronary artery anomalies are a diverse group of congenital disorders whose manifestations and pathophysiological mechanisms are highly variable, with a global incidence of $5.64 \%$ [1]. The classification of coronary anomalies is based on the abnormalities seen in one or more site of origin, course, termination and branches of the major coronary arteries. Some of these anomalies are common, while others are rare, like super-dominant right coronary artery (RCA) and left anterior descending artery (LAD) arising from the right coronary sinus [1].

\section{Case report}

A 65-year-old patient presented with exertional chest discomfort. Coronary angiogram showed super-dominant RCA originating from the right coronary sinus. The RCA gave rise to the left circumflex artery (LCA) as a distal branch, which passed to the posterior cardiac crux and continued to the left atrioventricular groove parallel to the coronary sinus. The angiogram also showed the $L A D$ artery originating from the right coronary sinus but from a different ostium (Figure $1 \mathrm{~A}$ ). Cardiac computed tomography was obtained and confirmed these findings. It also demonstrated the anterior free wall course of LAD (Figure 1 B).

\section{Discussion}

Super-dominant RCA with absent LCA is a very rare anomaly with few reported cases in literature. This sub- type of coronary anomalies is named type R-IA according to Lipton's classification and is by far the rarest type of single coronary artery, with an incidence of $0.0008 \%$ [2]. In this anomaly, the left main coronary artery continues as the LAD, while the RCA continues or gives rise to a distal branch that courses retrogradely to the left atrioventricular groove (i.e. the normal course of the left circumflex artery and coronary sinus) then to the left ventricle posterolateral wall (i.e. the LCA territory) [2].

The LAD originating from the right coronary cusp is another rare congenital anomaly where the LAD can have different courses, i.e. the anterior free wall course (as in this case), septal course or inter-arterial course [3].

This paper presents an extremely rare combination of two rare congenital anomalies coexisting; the super-dominant RCA and LAD arise from the right coronary sinus but from different ostia, and the LAD has an anterior wall course. There are 2 reported cases of super-dominant RCA, absent LCA and LAD originating from the right cusp, but in one case the LAD originated from the same ostium of the super-dominant RCA, while in the other case the LAD originated from different ostia but had a septal rather than an anterior free wall course [4]. To our knowledge, this combination of coronary congenital anomalies has not been described in literature before.

\section{Conflict of interest}

The authors declare no conflict of interest.

\section{Corresponding author:}

Tariq Enezate MD, Division of Cardiology, School of Medicine, University of Missouri-Columbia, 5 Hospital Drive, 65201 Columbia, USA, phone: 5738827272, e-mail: enezatet@health.missouri.edu

Received: 1.08.2016, accepted: 19.09.2016. 
Before PCI
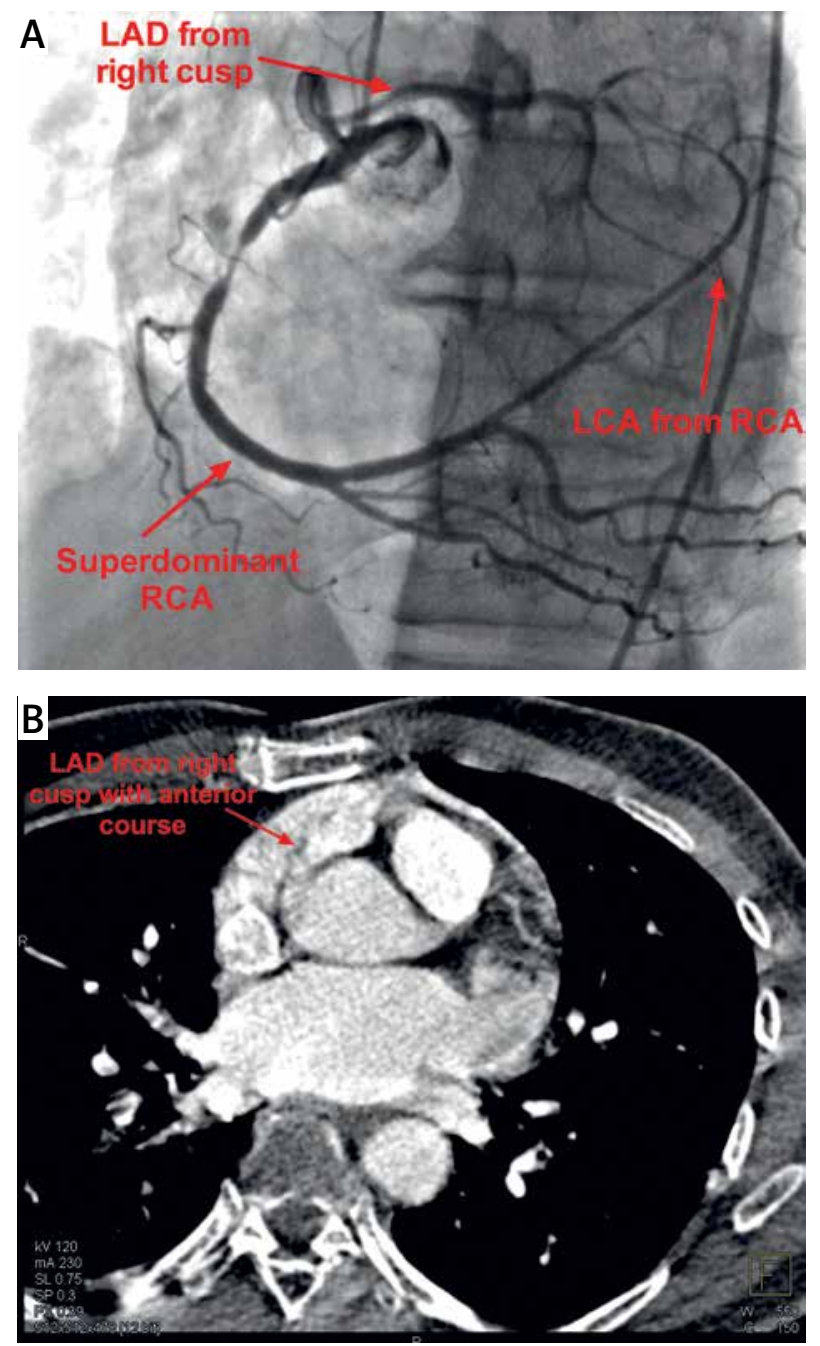

\section{References}

1. Angelini P. Coronary artery anomalies: an entity in search of an identity. Circulation 2007; 115: 1296-305.

2. Majid Y, Warade M, Sinha J, et al. Superdominant right coronary artery with absent left circumflex artery. Biomed Imaging Interv J 2011; 7: e2.

3. Gandhi H, Rosenberg M. Anomalous origin of the left anterior descending artery from a separate ostium of the right sinus of valsalva with abnormal stress test. Available at: http://www. hcplive.com/journals/cardiology-review-online/2007/may2007/ may-2007-gandhi. Accessed June 01, 2016.

4. Vijayvergiya R, Kumar Jaswal R. Anomalous left anterior descending, absent circumflex and unusual dominant course of right coronary artery: a case report--R1. Int J Cardiol 2005; 102: 147-8.

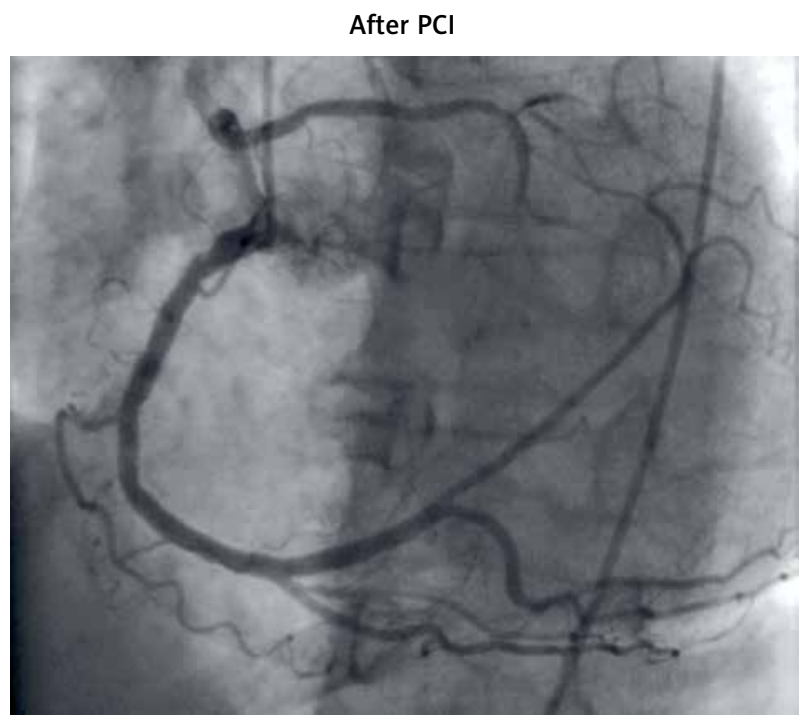

Figure 1. Coronary angiogram showing the three coronary vessels at once: (A) super-dominant RCA giving rise to LCA and LAD arising from right coronary sinus before and after percutaneous coronary intervention ( $\mathrm{PCl}$ ) and (B) computed tomography scan showing LAD arising from right coronary sinus with anterior free wall course 